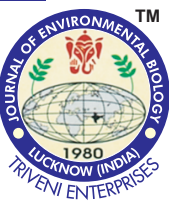

\title{
Comparing the performance of greenhouse crop transpiration prediction models based on ANNs
}

\section{Authors Info}

G. Jiankun ${ }^{1,2}$, L. Yanfei ${ }^{1}$,

L. Zengjin', G. Xuewen ${ }^{1 *}$ and

X. Cundong'

${ }^{1}$ North China University of Water

Resources and Electric Power,

Zhengzhou 450011, P.R. China

${ }^{2}$ Henan Key Laboratory of WaterSaving Agriculture, Zhengzhou 450011, P.R. China

*Corresponding Author Email : 54012012@qq.com

\section{Edited by}

Prof. Muhammad Aqeel Ashraf

\section{Reviewed by}

Dr. Luo Qiang

Dr. Wan Zhen

\section{Abstract}

Aim: This study analyzes the change rules between greenhouse crop transpiration and major indoor environment factors, builds two neural network prediction models of greenhouse eggplant transpiration rate based on BP and RBF and examines the performances of transpiration prediction models between different neural network methods.

Methodology: In order to evaluate the performance of greenhouse crop transpiration prediction models based on different ANNs, two most promising networks, Back Propagation (BP) and Radial Basis Function (RBF) neural networks were applied to create prediction models for eggplant transpiration in a Venlo-type greenhouse, located in North China. In this work, the change rules between measured transpiration rate and indoor major environment factors were analyzed, and 5 key inputs of the network structure were selected, such as indoor ground temperature, plant canopy temperature, solar radiation, relative humidity and pan evaporation. With the same network topological structure of 5-11-1 and same test data, two neutral network models were created by using neural network toolbox in MATLAB.

Results: After the comparative analysis of the results, it was indicated that: Both models in the same condition were acceptable, and the efficacy indictor (EI) of models were more than $90 \%$, relative errors (RE) between predicted and measured values were less than 0.30 . Furthermore, the RBF neural network model provided faster learning speed and higher precise results, and the average relative error of it was $0.56 \%$, less than $\mathrm{BP}(2.99 \%)$.

Interpretation: The results indicate that the RBF neural network model is more advantageous to predict the greenhouse crop transpiration under similar conditions, and may be recommended for practical application.

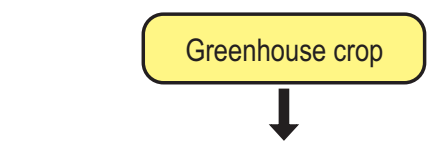

Analysis and Selection of major Influence

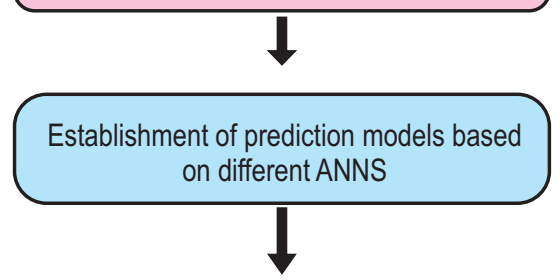

Evaluating the performance of two prediction models

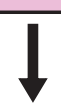

Obtaining the conditions and giving recommendations

Key words: Back propagation, MATLAB neural, Network tool box, Prediction model, Radial Basis Function

Citation: Jiankun, G., L. Yanfei, C. Chaodi, G. Xuewen, Y. Hongzhuo and W. Ziyu: Comparing the performance of greenhouse crop transpiration prediction models based onANNs. J. Environ. Biol., 40, 418-426 (2019) 


\section{Introduction}

The greenhouse vegetable cultivation is rapidly developing in China (Liao, 2016; Zhou and Wang, 2013; Wei and Sun, 2014), and the indoor environment is very different from the outdoor environment (Kiyan et al., 2013; He, 2014; Aldaihani and Raslan, 2017; Mahato et al., 2018). Greenhouse is a relative closed system with remarkable micro-climate effect where the indoor environment factors have multiple correlations with each other, and there are more complex nonlinear relationships between transpiration and environment factors (Gerasimov and Lyzlova, 2014; Wang et al., 2013). Different from the outdoors, the indoor crop transpiration rule has its unique characteristics (Ge et al., 2015; Bumidin et al., 2018; Emelue and Omonzogbe, 2018).

Crop transpiration is mainly measured by transpiration rate, which plays an important role in crop water requirement ( $\mathrm{Li}$ and Zhou, 2015). From the point of research progress at home and abroad, the research on crop transpiration rate is mainly based on linear or non-linear regression equation (Wang et al., 2015). But these methods have limitation in practical applications, as these methods are not applicable to analyze data without a certain statistical distribution, the dimension is difficult to determine and the randomness and volatility of nonlinear data has a big contribution to poor predict precision. Greenhouse is a relatively closed system, and there are more complex nonlinear relationships between transpiration and environment factors than outdoors, so the indoor crop transpiration rule cannot be described by regression simply (Zhang et al., 2015; Razzak et al., 2018).

As an interdisciplinary theory, artificial neural network models are widely used. Currently, it is widely being used in the areas of system identification, signal processing, prediction and mechanical control (Zou et al., 2014; Zakerzadeh et al., 2010; Ememu and Nwankwoala, 2018; Ma and Huang, 2007; Rajesh et al., 2013; Gai et al., 2015; Wang et al., 2014). The neural network model can be used as a black box system for estimating crop transpiration rate by establishing a nonlinear prediction model. This method effectively reduces the estimation error (Sun et al., 2014; Joghataie and Farrokh, 2011; Kibria et al., 2018). Several neural network prediction models are practiced in crop water requirement prediction according to indoor or outdoor environmental factors, among which BP neural network model and RBF network model are the two most popular models (Liu et al., 2013; Hanafiah et al., 2017; Lijie and Feng, 2018).

In the past, the BP neural network has been used more in artificial neural network. It is a multi-layer feed forward network with hidden layers, which could systematically solve the learning problem of hidden layer cell connection rights in multi-layer networks, however, its complex and unfixed network structure limits the learning speed and modelling efficiency. In addition to the BP neural network, a common network based on Radial Basis
Function (RBF) is popular too, which has a more simple network structure and a faster learning speed, may perform better than the BP network in greenhouse application (Liu et al., 2013; Li et al., 2018; Khattak et al., 2018).

The performance of greenhouse crop transpiration prediction models, based on ANNs, has been rarely evaluated, especially in greenhouse. High performance of the model arises from appropriate network types and structures. However, which method is more suitable for estimating greenhouse crop transpiration is still inconclusive. Therefore, this study analyzes the change rules between greenhouse crop transpiration and major indoor environment factors, builds two neural network prediction models of greenhouse eggplant transpiration rate based on BP and RBF respectively, and examine the performances of transpiration prediction models between different neural network methods.

\section{Materials and Methods}

Study area: The experimental study on transpiration rate prediction model was carried out in the winter of 2014 at Henan Key Laboratory of Water-Saving Agriculture, North China University of Water Resources and Electric Power, Zhengzhou City.

The greenhouse was a glass one of Venlo type equipped with heating, ventilation, fertigation, sunshade and all-time test measurement system, could take a real-time for the indoor meteorology, irrigation, drainage, soil moisture content and crop physiological status. The greenhouse was made of steel frame with a covering area of $537.6 \mathrm{~m}^{2}(19.2 \mathrm{~m} \times 28 \mathrm{~m})$, span of $9.6 \mathrm{~m}$, roof height of $4.73 \mathrm{~m}$, roof angle of $22^{\circ}$, top ventilation of $27 \%$ and domestic cover material of $4 \mathrm{~mm}$ float glass. The other specific parameters of the greenhouse structure is shown in Table 1.

Eggplant was cultivated in the greenhouse with drip irrigation under mulch, using an inlays-type drip irrigation belt as drip irrigation system, drip spacing of $30 \mathrm{~cm}$, the line source moist situation were formed in the field. The upper limit irrigation was $80 \%$ field water capacity, which could be controlled by Time Domain Reflect meter (TDR).

Data collection: The indoor meteorology parameters, such as ground temperature(Ts), relative humidity $(\mathrm{RH})$, plant canopy temperature (Tp), solar radiation $(\mathrm{Ra})$ were collected automatically by corresponding sensors connected to the LPS-05 type of plant growth monitoring device, and the data-collection interval was set 0.5 hour; Pan evaporation (E) was observed manually once a day at 9:00 am; Greenhouse eggplant transpiration rate ( $\mathrm{Tr}$ ) was measured by fast weighing method as perEq.1.

$$
T_{\mathrm{r}}=\frac{\Delta \mathrm{m}}{A \cdot \Delta t}
$$


Table 1: Table of model parameters

\begin{tabular}{llll}
\hline Parameters & Symbol & Value & Units \\
\hline Greenhouse volume & $\mathrm{V}$ & 2150.6 & $\mathrm{~m}^{3}$ \\
Ground area & $\mathrm{A}_{\mathrm{s}}$ & 537.6 & $\mathrm{~m}^{2}$ \\
Crop planting area & $\mathrm{A}_{\mathrm{p}}$ & 510.0 & $\mathrm{~m}^{2}$ \\
Covering surface area & $\mathrm{A}_{\mathrm{c}}$ & 927.6 & $\mathrm{~m}^{2}$ \\
Vent area & $\mathrm{A}_{\mathrm{v}}$ & 145.2 & $\mathrm{~m}^{2}$ \\
Light transmittance of glass & $\mathrm{T}_{\mathrm{a}}$ & 0.89 & 1 \\
\hline
\end{tabular}

Where, $T_{r}$ is the transpiration rate $\left(\mathrm{g} \cdot \mathrm{m}^{-2} \cdot \mathrm{h}^{-1}\right) ; \Delta \mathrm{m}$ is the leave weighing difference at two time $(\mathrm{g}) ; A$ is the leaf area of branches $\left(\mathrm{m}^{2}\right) ; \Delta \mathrm{t}$ is the measurement time $(\mathrm{hr})$.

Influence parameters analysis: Due to significant microclimate effect in greenhouse, crop transpiration is interrelated to environmental factors. So it is uncertain in choose input parameters of the prediction model. In order to find out the key influence factors and to facilitate the establishment of prediction model, it is necessary to analyze correlation between environmental factors and crop transpiration.

Data normalization process: As the original data collected was not in the same order of magnitude, to improve the accuracy of neural network training, all the data to be mapped to $[-1,1]$ was required for normalization process. MATLAB provides the data normalization processing functions as follow:

$$
[p n, \min p, \operatorname{maxp}]=\operatorname{premnmx}(p)
$$

Specific algorithm:

$$
p n=\frac{2(p-\min p)}{\max p-\min p}-1
$$

Reverse normalization processing function:

$$
p=p o s t m n m x(p, \min p, \max p)
$$

Execution algorithm:

$$
p=0.5(p n+1)(\max p-\min p)+\min p
$$

Where, $p$ is a set of data collected, $\min p$ is the smallest value of this set of data, max $p$ is the maximum of this set of data, $p n$ is the mapped data.

Design neural network models: As a comparison, two neural network prediction models of greenhouse eggplant transpiration rate were build based on $B P$ and $R B F$, respectively. The two models were built using neural network toolbox in MATLAB and a three-layer network structure containing one hidden layer was used to build these models, with consistent ground temperature (Ts), relative humidity $(\mathrm{RH})$, plant canopy temperature $(T p)$, pan evaporation (E), solar radiation ( $\mathrm{Ra}$ ) as input and observed crop transpiration rate as output. Training sample data was obtained from the cardinal-numbered days during the experiment.
Through trial calculation by experience formula, it was determined that 9 neurons in the hidden layer were proposed ultimately for both of the two neural network models (Yang et al., 2014; Noor et al., 2018). So, the neural network models both had a final topology of 5-11-1. Model design processes were as follows.

In the BP network model training, "Levenberg Marquardt" was regarded as the network learning algorithm (Wu et al., 2005), "tansig" as the transfer function of input layer and hidden layer, "purelin" as the transfer function of output and "trainscg" as training function. As shown in Fig.1, the training process of BP network didn't stop until the $265^{\text {th }}$ iteration, when the total square error reached the control value of network $\left(1 \times 10^{-12}\right)$. With the absolute error of network maintained at $(-1,1)$, it could be regarded that the accuracy of the model reached the training terminated (Fig.1).

In the RBF network model training, "newrb" is regarded as the function to design RBF network (Liu et al., 2013). Its call form as follow:

$$
\text { net }=\text { newrb }(p, t, G O A L, S P R E A D, M N, D F) \quad(E q .6)
$$

Where, $p, t$ are respectively for the input sample vector and the output sample vector; GOAL is the target error, which is 0.0001 ; SPREAD is extended constant, $S P R E A D=1 ; M N$ is the largest neuron number; $D F$ is the display frequency of iterative process, DF $=1$. As shown in Fig.2, the iteration process of training terminated after 178 times, when the error of the network achieved its predetermined value, with the absolute error of the network maintained at $(-1,1)$, the training terminated (Fig.2).

Performance Indicators: The performance indicator of efficacy indictor (EI) was used to show the validity degree of prediction models, higher the El value, better was the performance of model. The performance indicator of relative error (RE) was used to evaluate the prediction accuracy of models, and RE measured the deviation in transpiration rate from the desired target value. Smaller the RE value, better was the performance of the model. El and RE indicators were defined by the ASCE Task Committee and Kumar M. as Eq. 7 and Eq.8, respectively. 


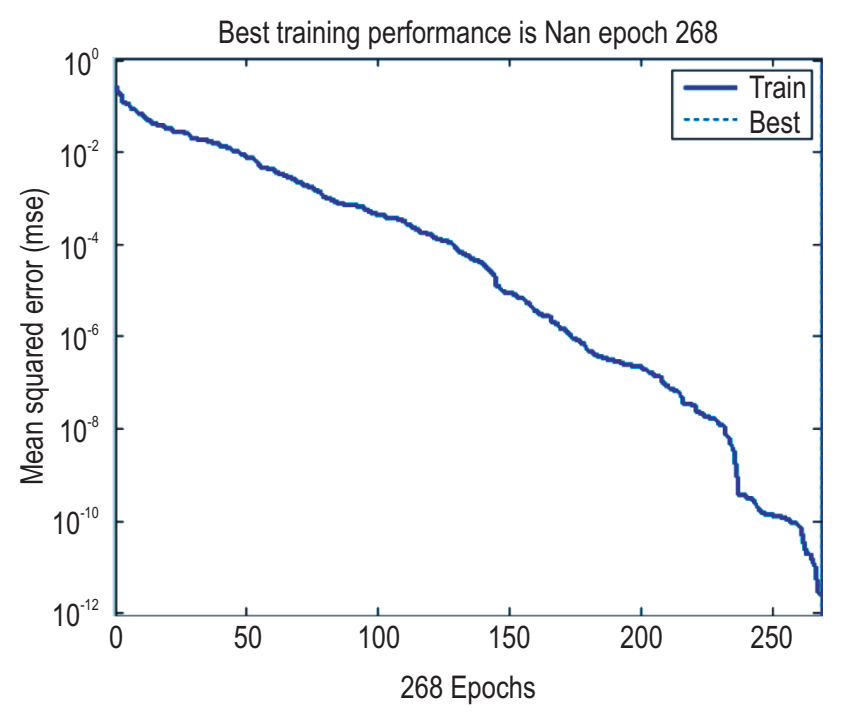

Fig. 1 : BP network training error decline curve.

$$
\begin{gathered}
\mathrm{RE}=\frac{y(i)-y_{m}(i)}{y(i)} \\
\mathrm{El}=\left[1.0-\frac{\sqrt{\sum_{i=1}^{N}\left(y(i)-y_{m}(i)\right)^{2}}}{\sqrt{\sum_{i=1}^{N}\left(y(i)-y^{2}\right.}}\right] \times 100 \%
\end{gathered}
$$

Where, $N$ is the number of samples, $y(i)$ is the system actual measured value, $y$ is the average of measured values and $y_{m}(i)$ is the predicted value of model

\section{Results and Discussion}

Relationship between greenhouse environment and crop ET: All the analysis was performed with SPSS. The change laws between the measured greenhouse eggplant transpiration rate and indoor various influence parameters were analyzed (Fig. 38). A correlation was observed between transpiration rate and indoor ground temperature $\left(R^{2}=0.6153\right)$, solar radiation ( $R 2=0.7943)$, pan evaporation $(R 2=0.8095)$, while negative was found with relative humidity indoor $\left(R^{2}=0.6646\right)$ and air pressure $\left(R^{2}=0.2009\right)$. It can be found that, the degree of correlation of other variables were so high that they could not be ignored, therefore, these five meteorological factors were selected as the main influence parameters to build the transpiration rate prediction models, based on neural networks in greenhouse.

Comparison between Back Propagation (BP) and Radial Basis Function (RBF) neural networks: The required data for evaluating and analyzing the performance of two models was

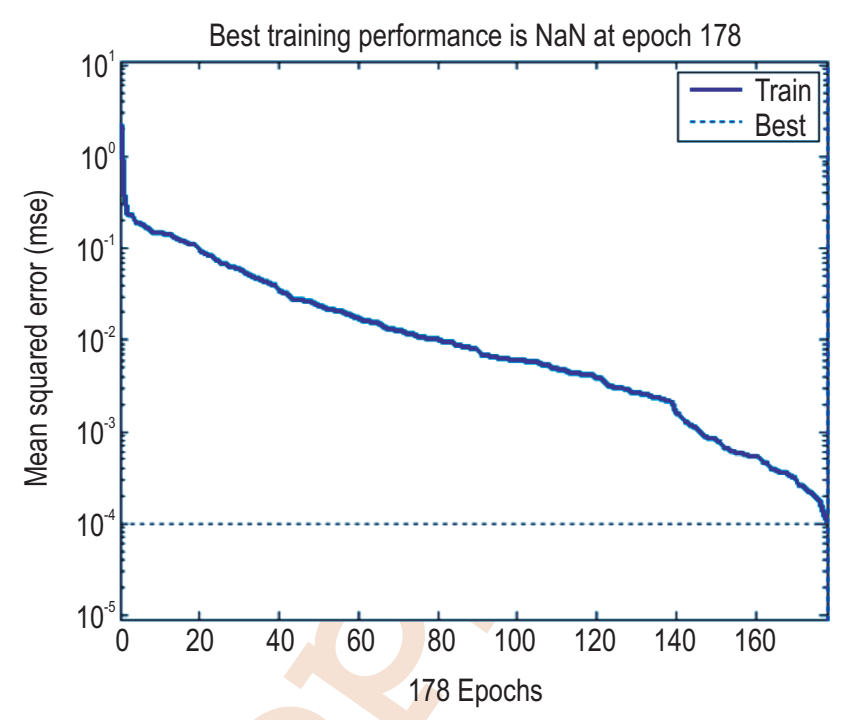

Fig. 2 : RBF network training error decline curve.

obtained in even-numbered days during experiment. After reverse normalized treatment, the prediction results of two models were compared to the measured values (Fig.8).

As shown in Fig.8, both of the two models' predictive resulting data based on BP and RBF neural networks, had a consistent trends with the measured data. According to Eq. 8, the efficacy index (EI) of the two models was calculated, and the results were $94.24 \%$ and $96.65 \%$ respectively, that indicated the validity of RBF based neural network model was a little better than the BP based neural network model. However, in the overall evaluation of both the neural network prediction models had a certain effectiveness, and both of the predicted results were ideal (Fig.8).

In order to evaluate the models' predicted accuracy, the relative errors between the two groups of predicted values $(\operatorname{Tr}(\mathrm{BP})$ and $\operatorname{Tr}(\mathrm{RBF}))$ and the measured values $(\operatorname{Tr})$ were calculated in this study. According to Table 1, both of the two models' predicted errors were in the range of -0.3 to 0.3 . In addition, there apeared some large deviations between the predicted and the measured values during the test (e.g. Dec 20th and Dec 30th). According to measured data observation, it was found that these large deviations appeared mainly in changeable weather when various greenhouse regulation measures would produce certain interferences in the models, resulting in decreased prediction accuracy and appear large deviations. However, overall evaluation of both of the predicted results were satisfactory.

Our findings suggest that using meteorological data as input factors, the practicability of artificial neural network model can be improved, and it realizes the real prediction on greenhouse crop transpiration, unification of precision and 


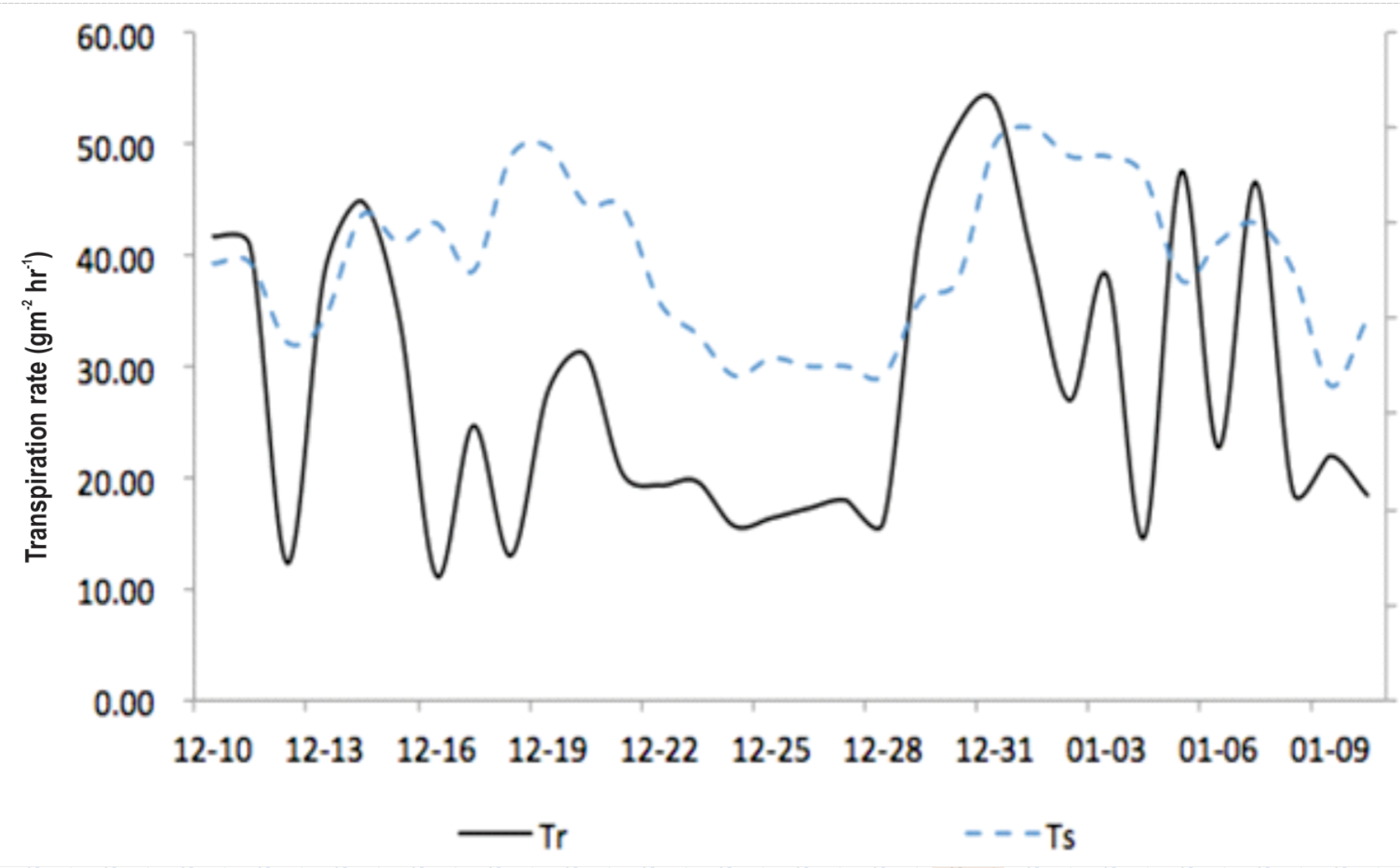

Fig. 3 : Transpiration rate and ground temperature.

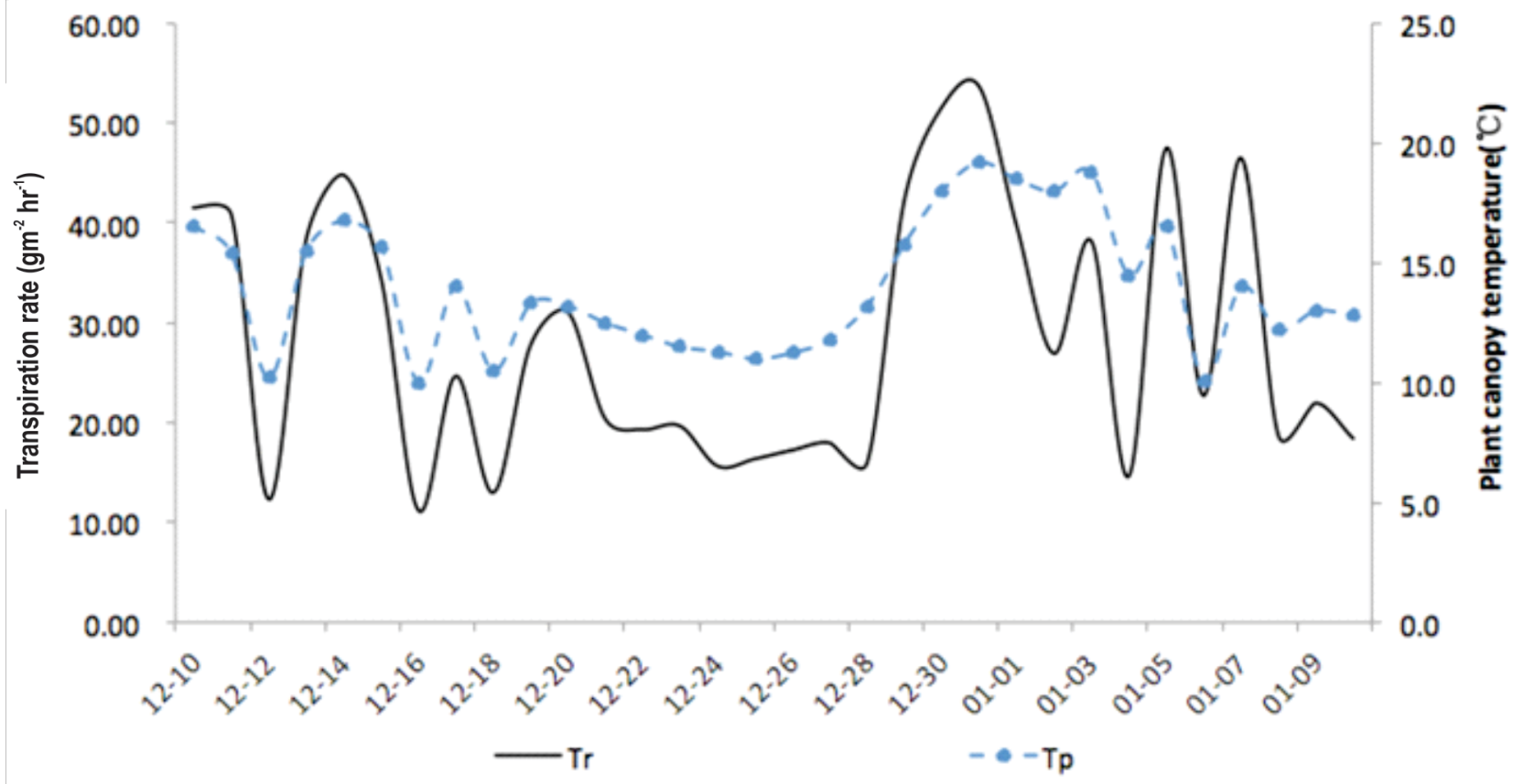

Fig. 4 : Transpiration rate and plant canopy temperature.

practicability of these models. This finding is in confirmation with the previous study carried on both field and greenhouse crops (Sun et al., 2014). The neural network has a self-learning characteristic, which can be used as an effective non-linear fitting method and can learn the potential rules between the crop and various influence factors in the greenhouse (Ma and Huang, 2007; Rajesh et al., 2013).

Through model validation, it is proved that the prediction models based on BP and RBF neural networks are both effective 


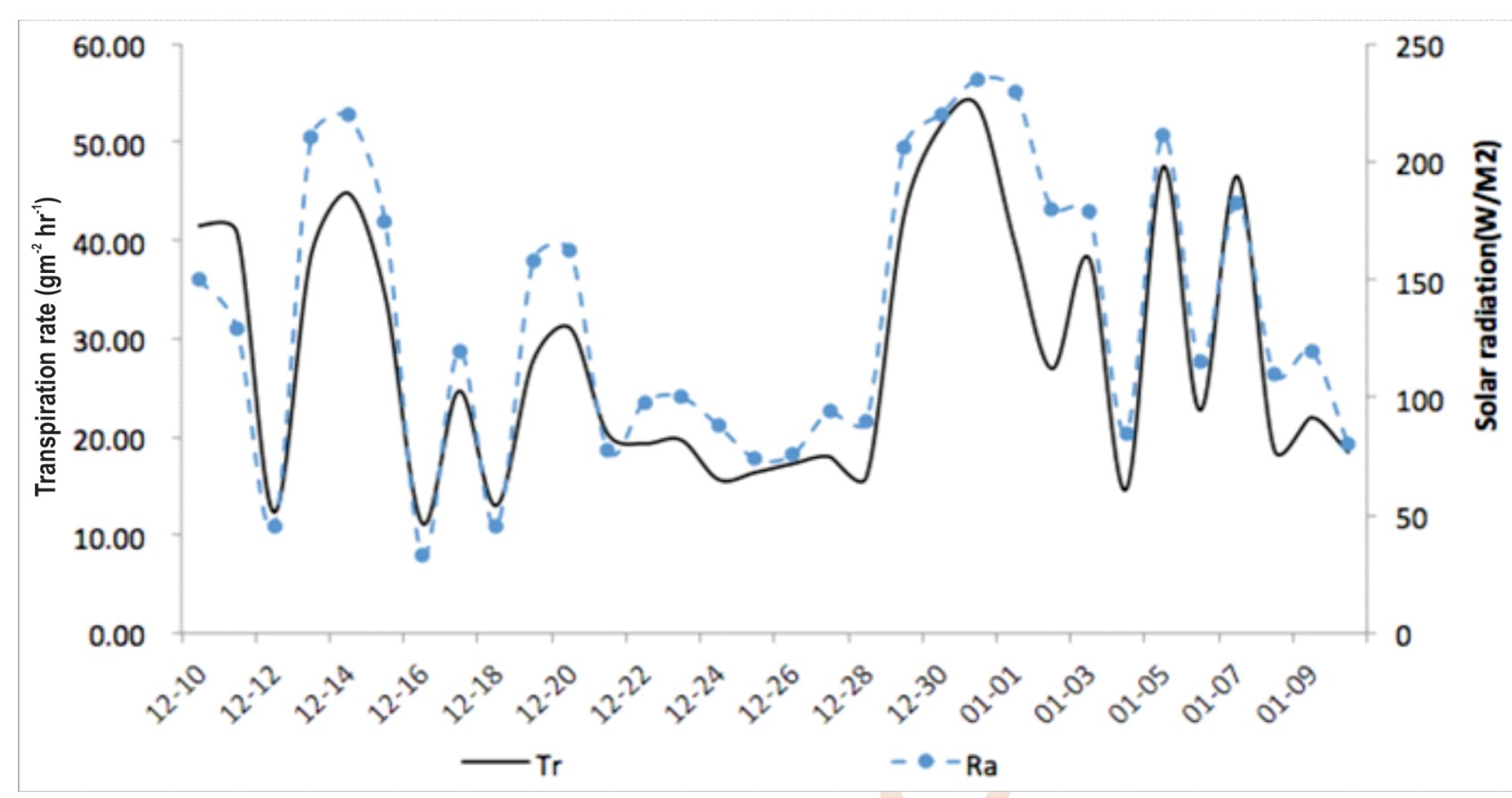

Fig. 5 : Transpiration rate and solar radiation.

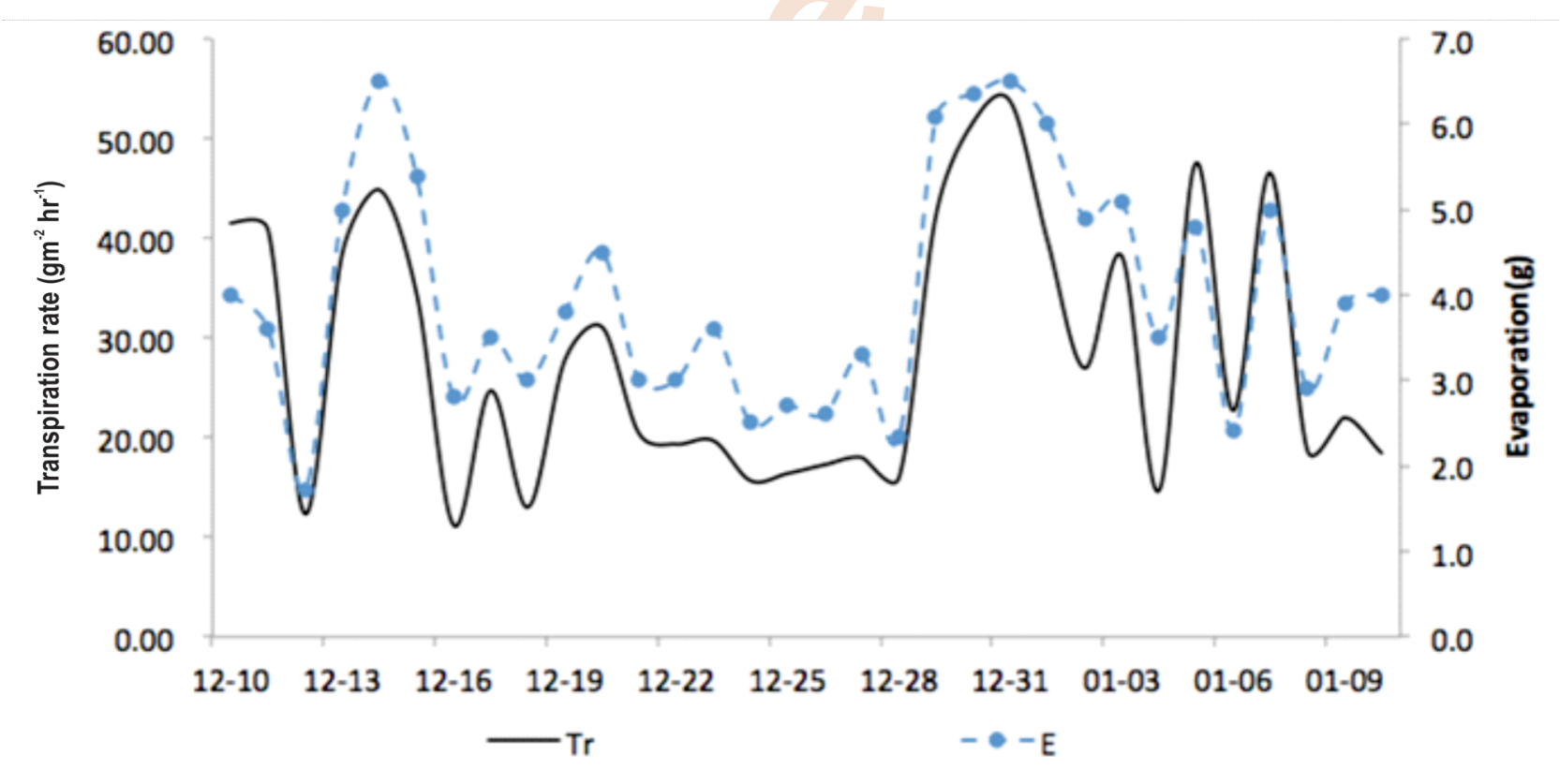

Fig. 6 : Transpiration rate and air pressure.

for projecting greenhouse eggplant transpiration rate, and both has high prediction accuracy (Zakerzadeh et al., 2010). Furthermore, our findings suggest that compared with the BP network, which has been used more in artificial neural network in the past, the advantages of this RBF network were reflected in the following aspects: the RBF network model training took less time (Xu and Wu, 2002). It has been reported that the iterations in RBF network training process in the MATLAB was 178 times, while BP network need 265 times. Apparently, RBF neural network training is of better practical value; the predicted accuracy of RBF based 


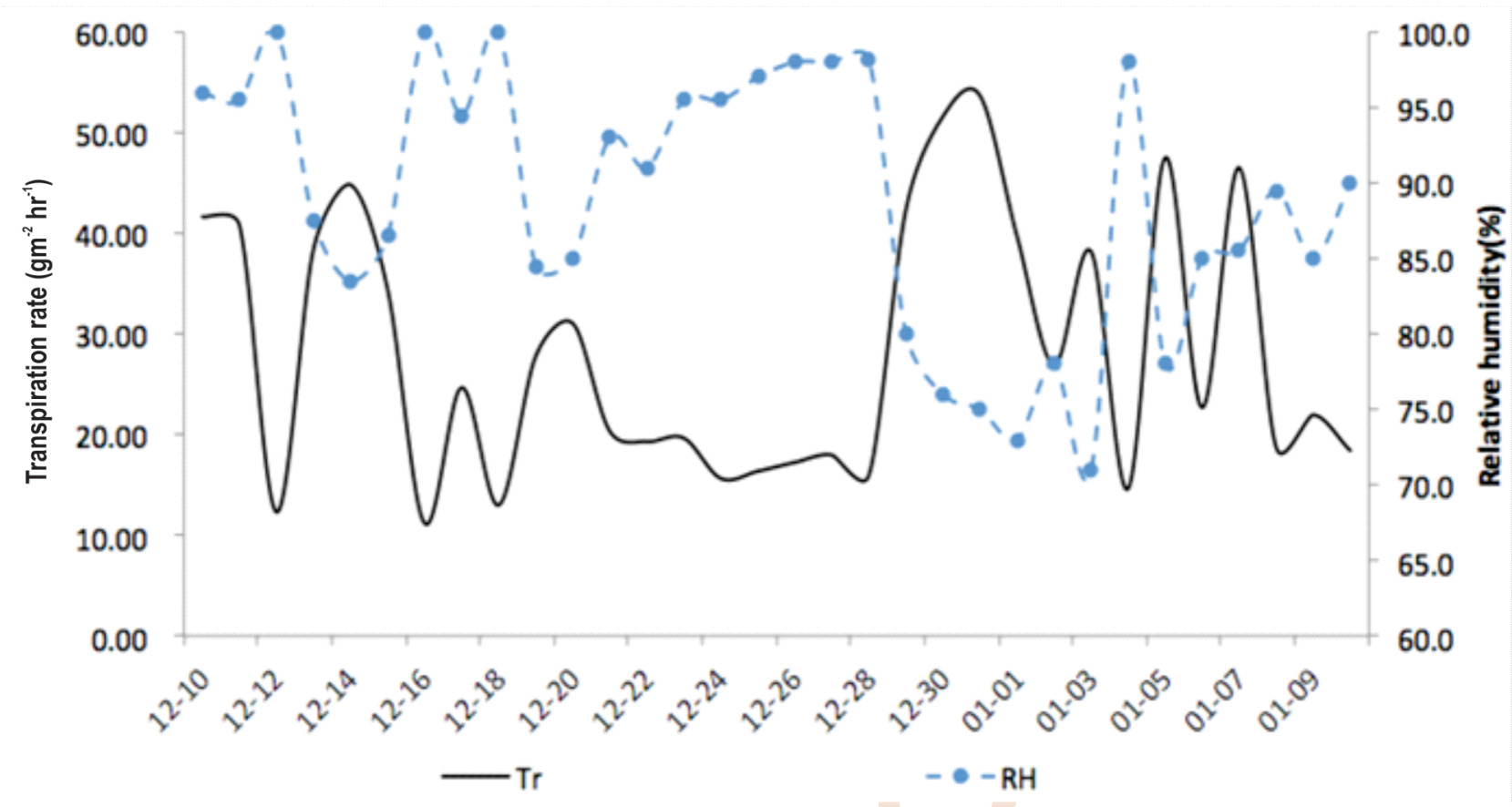

Fig. 7 : Transpiration rate and relative humidity.

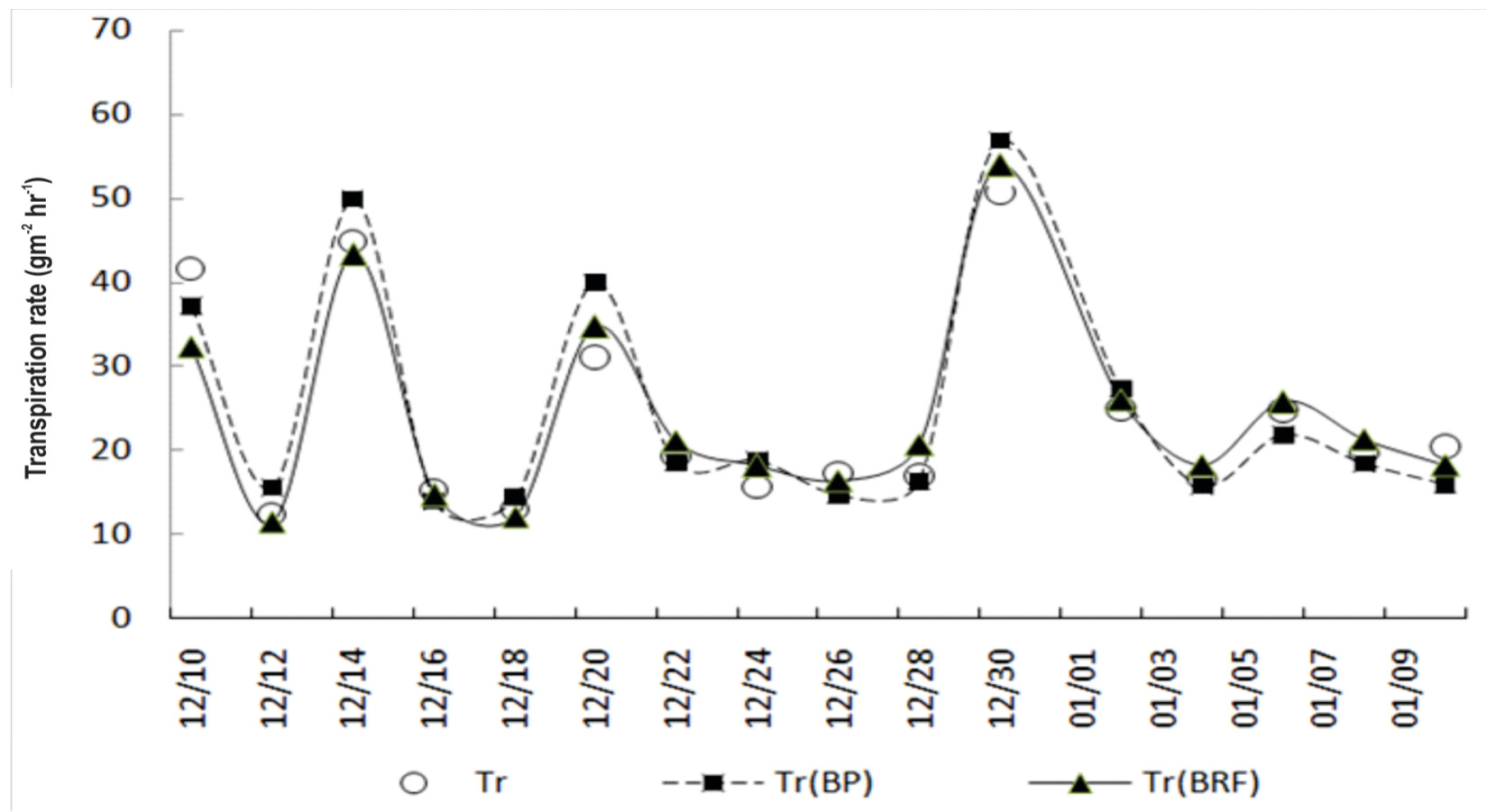

Fig. 8 : Forecast results of two models.

model was higher, and it showed a better prediction ability than BP network model; the pan evaporation had a high correlation with crop transpiration and it is supposed to be a key input factor of the model structure, and new network structure including pan evaporation had a higher predicted accuracy.
In this study, two popular artificial neural networks for predicting crop transpiration were evaluated for greenhouse eggplant with drip irrigation under mulch condition in the North China. The RBF neural network model had more advantages than BP neural network for predicting the greenhouse crop 
Table 2: BP, RBF neural network models' predicted results

\begin{tabular}{|c|c|c|c|c|c|}
\hline Date & $\begin{array}{l}\mathrm{Tr} \\
\mathrm{g} \cdot \mathrm{m}^{-2} \cdot \mathrm{h}^{-1}\end{array}$ & $\begin{array}{l}\operatorname{Tr}(B P) \\
g \cdot m^{-2} \cdot h^{-1}\end{array}$ & $\mathrm{RE}(\mathrm{BP})$ & $\begin{array}{l}\operatorname{Tr}(\text { RBF }) \\
g \cdot m^{-2} \cdot h^{-1}\end{array}$ & $\mathrm{RE}$ (RBF) \\
\hline $12-10$ & 41.58 & 37.18 & -0.1058 & 32.33 & -0.2226 \\
\hline $12-12$ & 12.31 & 12.59 & 0.0224 & 10.48 & -0.1490 \\
\hline $12-14$ & 44.82 & 49.91 & 0.1134 & 49.32 & 0.1004 \\
\hline $12-16$ & 11.20 & 12.95 & 0.1570 & 12.71 & 0.1353 \\
\hline $12-18$ & 13.00 & 14.42 & 0.1096 & 15.17 & 0.1671 \\
\hline $12-20$ & 31.05 & 39.94 & 0.2860 & 34.69 & 0.1172 \\
\hline $12-22$ & 19.31 & 19.49 & 0.0098 & 16.14 & -0.1641 \\
\hline $12-24$ & 15.65 & 18.77 & 0.1992 & 18.21 & 0.1634 \\
\hline $12-26$ & 17.25 & 14.67 & -0.1495 & 16.43 & -0.0477 \\
\hline $12-28$ & 15.98 & 14.34 & -0.1026 & 18.70 & 0.1698 \\
\hline $12-30$ & 51.62 & 62.81 & 0.2167 & 43.96 & -0.1484 \\
\hline 01-02 & 26.93 & 27.25 & 0.0118 & 26.07 & -0.0320 \\
\hline 01-04 & 14.63 & 14.78 & 0.0106 & 12.26 & -0.1622 \\
\hline 01-06 & 22.69 & 21.85 & -0.0369 & 25.78 & 0.1362 \\
\hline 01-08 & 18.71 & 18.40 & -0.0168 & 22.38 & 0.1958 \\
\hline $01-10$ & 18.42 & 13.89 & -0.2460 & 15.31 & -0.1690 \\
\hline
\end{tabular}

transpiration rate under similar conditions, which is proposed to be used in future study. The study has an important guiding significance for water requirement rule and irrigation management of greenhouse crop with drip irrigation under mulch.

In this study the network model parameters were obtained under certain natural conditions and farmland management level. The artificial neural network models cannot reflect the relationships between different environmental factors. This is the inevitable limitation of the artificial neural network, so it has certain application scope, which is suitable to the similar situation and similar area in China.

\section{Acknowledgments}

This publication is supported by the National Natural Science Foundation of China (51709110, 51809094, 51779093), the Natural Science Foundation of Henan Province of China (162300410138), the Foundation of Henan Educational Committee (18A570005) and the Program for Innovative Research Team in Henan University (19IRTSTHN030).

\section{References}

Aldaihani, N. and A. Raslan: Estimation of $\mathrm{CO}_{2}$ emissions of the vehicles transport sector in the State of Kuwait. Acta Chem. Malay., 1, 0812(2017).

Bumidin, M.S., F.A. Johari, N.F. Risan and M.H. Mohd. Nasir: The effect of aqueous extracts of nigella sativa on breast cancer cell line Mcf7: An in vitro study. Sci. Herit. J., 2, 13-17(2018).

Clemmens, A.J., T.F. Kacerek, B. Grawitz and W. Schuurmans: Test cases for canal control algorithms. J. Irrig. Drain. Engg.: (ASCE), 124, 23-30 (1998).

Emelue, G.U. and E.A. Omonzogbe: Growth performance of african giant land snails (Archachatina marginata) fed with feed formulated with different calcium sources. Malays. J. Sustain. Agric., 2, 01-04 (2018).

Ememu, A.J. and H.O. Nwankwoala: Application of water quality index (Wqi) for agricultural and irrigational use around Okpoko, Southeastern Nigeria. Eng. Herit. J., 2, 14-18 (2018).

Gai, J.F., G.R. Zhao and C. Song: Model predictive control based on linearization and neural network approach. J. Syst. Eng. Electron., 39, 394-399 (2015).

Ge, J.K., J. Li and J.Y. Luo: Water requirement calculation model of tomato with drip irrigation under mulch in sunlight greenhouse based on water surface evaporation method. J. Irrig. Drain Eng., 34,53-56 (2015).

Ge, J.K., N. Lian and H.J. Lei: Prediction model of greenhouse eggplant transpiration based on RBF neural network. J. Resi. Sci. Technol., 13, 134 (2016).

Gerasimov, D.N. and M.V. Lyzlova: Adaptive control of microclimate in greenhouses. J. Comput. Syst. Sci. Int, 53, 896-907(2014).

Hanafiah, M.M., M.Y.M. Ali, N.I.H.A. Aziz and A. John: Biogas production from agro-waste and effluents. Acta Chem. Malay., 1, 13-15 (2017).

He, H.B.: Build scheme of internet of greenhouses-oriented agriculturegreenhouses at low cost in Fujian. J. Minj. Univ., 5, 81-87(2014).

Joghataie, A. and M. Farrokh: Matrix analysis of nonlinear trusses using Prandtl-2 neural networks. J. Sound. Vib., 330, 4813-4826 (2011).

Khattak, A.M., Z. UI-Haq, Z. Barki and M. Ilyas: Application of soft P-open set to binary soft structures. Acta Sci. Malays., 2, 23-26 (2018).

Kibria, A.A., Kamrunnessa and M.M. Rahman: Extraction and evaluation of phytochemicals from green coconut (Cocos nucifera) shell. Malays. J. Halal Res., 1, 19-22 (2018).

Kiyan, M., E. Bingöl, M. Melikoglu and A. Albostan: Modeling and simulation of a hybrid solar heating system for greenhouse applications using Matlab/Simulink. Energy Convers. Manage., 72, 147-155(2013).

Kumar, M., N.S. Raghuwanshi and R. Siongh: Estimating evapotranspiration using artificial neural network. J. Irrig. Drain. Engg.: (ASCE), 128, 224-233(2002).

$\mathrm{Li}, \mathrm{Y}$. and M. Zhou: Variation trends in water requirement of cotton and 
sugar beet in Xinjiang under climate change scenarios. Transactions of CSAE, 31, 121-128 (2015).

$\mathrm{Li}, \mathrm{Y}$. , P. Yang and H. Wang: Collecting coal fired power environmental tax to promote wind power development and environmenta improvement. Acta Sci. Malays., 2, 05-08 (2018).

Liao, J.S.: Design of agricultural greenhouse environment monitoring system based on internet of things. Transactions of CSAE, 32 , 233-243 (2016).

Lijie, L. and Y. Feng: Astudy on the rhythm and respiratory characteristics of Zhuang language. Acta Sci. Malays., 2, 26-28 (2018).

Liu, J.R., J.J. Ma, Z. Wang and B.G. Ma: Crop water consumption forecast of walnut based on RBF neural networks and BP neural networks. Water Sav. Irrig., 39, 394-399 (2013).

Ma, Y.M. and M. Huang: Study of digit recognition based on BP neura network. Infor. Technol., 4, 84-88 (2007).

Mahato, S., S. Bhuju and J. Shrestha: Effect of Trichoderma viride as biofertilizer on growth and yield of wheat. Malays. J. Sustain Agric., 2, 01-05 (2018).

Mahmood, S., S.T. Kazmi and S.S. Ali: Comparison of drinking water bottles of different countries along with Zamzam Water, Pakistan. Earth Sci. Pak., 2, 05-14 (2018).

Nawaz, A., F. Arshad and F. Khurshid: Evaluation of low-cost environment friendly natural extracts for the purification of drinking water. Earth Sci. Pak., 2, 23-25 (2018).

Noor, N.M., I.A. Mohd Suberi, D. Susanti, Y. Mukail, A. Adam, S. Saad and F.A. Khodzori: The potential of dried and fresh extracts of Sanseviera trifasciata to mitigate Alexdrium tamiyavanichii, a toxic dinoflagellate. Sci. Herit. J., 2, 18-20 (2018).

Rajesh, S.V., T.N. Singh and P.G. Ranjith: A comparative study of generalized regression neural network approach and adaptive neuro-fuzzy inference systems for prediction of unconfined compressive strength of rocks. Neural Comput. Appl., 33, 499-506 (2013).

Razzak, M.A., M.A. Islam, M.H. Rahman, M.A. Sathi and M. Atikuzzamman: Screening of lentil germplasm against Stemphylium blight by observing disease reaction in three different stages. Malays. J. Halal Res., 1, 15-18 (2018).

Sun, G.X., T.T. Yan, X.C. Wang, M. Chen, Y. Zhang, J. Di, Y.Y. Shi and J.B. Chen: A method of cucumber transpiration rate forecast based on wavelet transform and dynamic neural network. J. Nanjing Agric. Univ., 37, 142-152 (2014).

Wang, L.S., T. Hou and M. Jiang: Improved multi-objective evolutionary algorithm for optimization control in greenhouse environment.
Transactions of the CSAE, 30, 131-137(2014).

Wang, M.M., B.F. Li and Y.Z. Shen: Linear regression with corrected errors of independent and dependent variables. J. Tongji. Med. Univ., 44, 446-453(2015).

Wang, Q., H.T. Zhang and X. Liu: Analysis on temperature, light in sinking solar greenhouse. Chin. J. Aeronaut., 34, 37-42(2013).

Wei, R.J. and Z.F. Sun: Development and perspective of research on microclimate of sunlight greenhouse in China. J. Northwest Univ., 42, 140-150(2014).

Wu, J.S., L. Jin and J.F. Nong: Forecast research and applying of bp neural networkbased on genetic algorithms. Mathemat. Pract. The., 35, 83-88 (2005).

$\mathrm{Xu}, \mathrm{D}$. and Z. Wu: MATLAB6. X system analysis and design. Xi'an University. Electronic Science. Technology. Press, Xi'an (2002).

Yang, Y., S.S. Gao, J.P. Wu and Y. Zhao: Feed-forward neural network alorithm based on model predictive filtering and its application in integrated navigation. J. Chinese Inertial Technol., 22, 221-226 (2014).

Young, M.H., P.J. Wierenga and C.F. Mancino: Monitoring near-surface soil water storage in turfgrass using time domain reflectometry and weighing lysimetric. Soil Sci. Soc. Am. J., 61, 1138-1146(2010).

Yue, X.G. and M.A. Ashraf: Opposite degree computation and its application. Eng. Herit. J., 2, 05-13 (2018).

Zahan, T., A. Hashem, M. Rahman, R.W. Bell and M. Begum: Efficacy of herbicides in non-puddled transplanted rice under conservation agriculture systems and their effect on establishment of the succeeding crops. Acta Sci. Malays., 2, 17-25 (2018).

Zakerzadeh, M.R., M. Firouzi, H. Sayyaadi and S.B. Shouraki: Hysteresis identification of shape memory alloy actuators using a novel artificial neural network based Presiach model. Proc, ASME 2010 Conf. on Smart Materials, Adaptive Structures and Intelligent Systems, New York, 1,653-660(2010).

Zhang, D.L., Z.D. Zhang and J.M. Li: Co-ordination of environmental factors in driving and regulating transpiration rate of greenhouse grown muskmelon. Transactions of the Chinese Society for Agricultural Machinery, 46, 137-144(2015).

Zhou, W. and X.C. Wang: Venlo-type greenhouse microclimate simulation research in the Plum Rainy Weather of South China. J. Agric. Res., 35, 190-193(2013).

Zou, Q.Y., J.W. Ji and Z.M. Li: Identification of greenhouse microclimate environmental factors prediction model based on ANFIS. J. Sheny. Agricul. Univer., 45, 503-507(2014). 